\title{
The Influence of Participation in Different Sports on Physical Health Perception among Inmates of Ilesa Prison in Osun State, Nigeria
}

\author{
Honestus Ayobami Obadiora* \\ Department of Physical \& Health Education, Obafemi Awolowo University, Ile-Ife, Nigeria \\ *Corresponding author: ayobadiora@yahoo.com
}

\begin{abstract}
Poor physical health condition is common among prison inmates due to movement limitation during confinement. The negative effects of custody on health can be reduced to a minimum with the principle that time spent in custody can be used to include participation in organised physical activities to promote physical health of inmates while in confinement. The study is aimed at determining the relationship between sport participation and physical health of inmates in Ilesa Prison in Osun State of Nigeria. The study employed experimental pretest - posttest control research design. This study was carried out over a 10 week period at the Ilesa prison in Osun State, Nigerian. 140 inmates were selected for the study. The respondents were grouped into four sports- athletics (sprints and relays), badminton, table-tennis and volleyball. The physical health domain of the World Health Organization Quality of Life Scale (WHOQOL-BREF) was adapted and used to determine the inmates' perception of their physical health. The data collected on reported physical health condition of inmates against the different categories of sport participation (athletics, badminton, table-tennis and volley-ball) of the respondents were analysed with descriptive and inferential statistics. Multiple regression analysis, Pearson's Product Moment Correlation Coefficients and Analysis of variance (ANOVA) were used to determine whether differences observed on the physical health perceptions by inmates and sports participation are significant. The study revealed a moderate correlation between participation in athletics and physical health $(\mathrm{r}=0.685)$; participation in Table Tennis and physical health $(\mathrm{r}=.697)$ and participation in volleyball and physical health $(\mathrm{r}=.504)$. It is therefore, concluded that participation in different sports can definitely influence the perception of physical health among inmates of Ilesa prison in Osun State of Nigeria.
\end{abstract}

Keywords: inmates, sport participation, physical health, prison, quality of life

Cite This Article: Honestus Ayobami Obadiora, "The Influence of Participation in Different Sports on Physical Health Perception among Inmates of Ilesa Prison in Osun State, Nigeria.” American Journal of Sports Science and Medicine, vol. 6, no. 2 (2018): 39-43. doi: 10.12691/ajssm-6-2-1.

\section{Introduction}

Physical activity, health and quality of life are closely interconnected. The human body was designed to move and therefore needs regular physical activity in order to function optimally and avoid illness [1]. It has been proved that a sedentary lifestyle, as common in confinement, is a risk factor for the development of many chronic illnesses, including cardiovascular diseases. Furthermore, living a physically active life brings many other social and psychological benefits and there is a direct link between physical activity and life expectancy, so that physically active populations tend to live longer than inactive ones. Sedentary or confined people who become more physically active report feeling better from both a physical and a mental point of view, and enjoy a better quality of life [2].

Contrasting inactivity and enhancing well-being is usually the first reason given when encouraging sports activities; indeed, there is a large body of literature showing that inactivity is one of the most significant cause of death, disability and reduced quality of life [3]. Also, it has been well demonstrated that daily participation in organised sport and physical activity maintains wellness and prevent a huge number of health problems. Generally speaking, inmates have few opportunities to practice sport regularly; they can be considered as a population presenting a high risk of hypokinetic diseases such as heart diseases, obesity, hypertension, osteoporosis and diabetes. Due to the incarceration, movement and occasions to practice sport are very limited with a consequent impossibility for inmates to enjoy the good effects of physical activities: though in such a kind of situation, those who are imprisoned retain their fundamental right to enjoy good physical and mental health [4,5].

Reference [6] defined health as "a state of complete physical, mental and social well-being, and not merely the absence of disease or infirmity." This definition emphasizes the multidimensional nature of health [7]. Participation in physical exercise can lead to a variety of social, psychological, and physical consequences 
[8]. Participation in regular physical activity has been associated with a variety of positive psychosocial effects ranging from a reduction in depressive symptoms [9] and anxiety to improvements in self-esteem [10] and a more positive self-concept and perception of the self by others [11].

The negative effects of custody on health can be reduced to a minimum with the principle that time spent in custody can be used positively to aid the prevention of disease and to promote health [12,13]. Indeed, a moderate participation in physical activity acts positively on the general health of sedentary population even whether there is a low level of physical involvement [14]. Sport based programmes are cost-effective way to tackle health problems and develop quality of life and thereby foster a general well-being: particularly, physical activity has positive effect for the general mental health of inmates and it can contribute to achieve higher level of general wellness [13].

\section{Materials and Methods}

\subsection{Study Setting}

The Nigerian Prisons Service, Ilesa Prison Yard, Ilesa, Osun State, Nigeria is a medium security facility, adjacent to Ilesa Police Area Command Headquarters in Ayeso, Ilesa East Local Government Area of Osun State. Ilesa Prison facility was commissioned in 1943 with capacity to accommodate 600 inmates while the 2013 number of inmates is put at about 526. Despite the population of the inmates which was below the prison capacity, beds and bedding in the prisons were inadequate. In some cells or prison blocks where beds are available, mattresses, bed sheets and blankets were lacking. The prison has an open space of about 60 by $80 \mathrm{~m}$ size meant for recreational sports and physical activities. The prison yard lacks basic equipment for sporting activities hence the playing field is hardly put into use.

\subsection{Type and Period of Study}

The study employed experimental pretest - posttest control research design. A total of 140 respondents were selected through purposive sampling technique. The study covered a period of ten weeks. The first week was used to administer pre-test questionnaire, the following eight weeks were used for sports participation. The eight weeks included two weeks of teaching on theory and techniques of sports-skills, rules and regulations and officiating as well as six weeks used for active sports practice and within sport group competition sessions. The respondents in experimental groups participated in sports activities for a period of two hours per day, twice (Tuesdays and
Wednesdays) per week for a period of six weeks. Attendance was marked before and after the events. The last week of the study was used for the administration of post-test questionnaire.

\subsection{Population and Sample Size}

The study population comprised male inmates in Ilesa Prison. Study respondents were selected using systematic random sampling technique. The study samples were 140 inmates within age 20 and 35 years, excluding inmates on death sentence and those undergoing medical and/or psychiatric treatment. Inmates within the age range were selected because young adulthood typically covers the period from 20-35 years of age, when both biological function and physical performance reach their peak [15]. The respondents were randomised into two groups of experimental and control. The inmates in experimental group were further grouped into each of the sport areas (athletics - sprints \& relays, badminton, table-tennis and volley-ball) to facilitate comparison of collected data for analysis.

\subsection{Data Collection}

The WHOQOL-Bref scale was used to measure the physical health domain of QOL -among inmates of Ilesa prison. The WHOQOL instrument was developed by WHO and simultaneously tested in diverse cultures across the world, this means that the instrument has a strong potential for easy cross-cultural applicability, since the items are framed in culture-neutral terminology [16]. The scale includes widely valued contextual factors of life that are not generally regarded as health-related. Therefore, it is a generic instrument for assessing general QOL [17]. The scale is used to investigate the physical health aspect of the quality of life among the prison inmates. Also, the study instrument includes the sport participation scale used to measure the respondents' attendance and self-reported proficiency in different sports (athletics- sprints and relay, badminton, table-tennis and volley-ball).

\subsection{Ethical Considerations}

The study was approved by the academic and postgraduate committees of the Obafemi Awolowo University as a doctorate requirement. Also, the study was approved by the State Comptroller of the Osun State Command of Nigeria Prison Service (NPS) following the advice of the command's legal officer. The study obtained a voluntary and written consent of the inmates to participate in the study. The inmates are fully aware of their right to withdraw from the study at any time during the period of the study.

Table 1. Sport Participation Schedule

\begin{tabular}{|c|l|l|c|c|}
\hline Week & Day & Activity & Duration \\
\hline 1 & Tuesday -Wednesday & Selection of respondents Pretest & $9.00-11.00$ AM \\
\hline $2-3$ & Tuesday -Wednesday & Theory and Practice of sports & $9.00-11.00$ AM \\
\hline \multirow{2}{*}{$4-9$} & Tuesdays & Sports Participation & $9.00-11.00$ AM \\
\cline { 2 - 4 } & Wednesdays & Sports Participation & $8: 30-10.30$ AM \\
\hline \multirow{2}{*}{10} & Tuesday & Posttest & $8: 30-10.30$ AM \\
\cline { 2 - 4 } & Wednesday & Sport Participation and Study Feedback & $8: 30-10.30$ AM & $2 \mathrm{hrs}$ \\
\hline
\end{tabular}




\subsection{Data Analysis}

The data collected on physical health perception were analysed by respondents in different sport areas (athletics -sprints \& relays, badminton, table-tennis and volley-ball) using descriptive and inferential statistics. Analysis of variance (ANOVA) was used to determine whether differences observed among respondents in different sports areas on perceived physical health domain of QOL measurements are significant. The regression analysis of the independent variables of different sports - athletics (sprints \& relays), badminton, table-tennis and volley-ball) was measured to determine the effect of different sport on physical health among inmates. Statistical significance was set at $\mathrm{P}<0.05$.

\section{Results}

The relationship between the sport participation and physical health scores were analysed using ANOVA, multiple regression analysis and Pearson's product moment correlation coefficients. The result of the analysis is presented in the Table 2 and Table 3.

The mean and standard scores of sport participation by sport sub-groups of athletics, badminton, table tennis and volleyball and physical health of respondents in control and experimental groups were presented in Table 2 while Table 3 shows analysis of variance (ANOVA) of the relationship between sport participation and physical health perception of inmates in Ilesa prison. All the results of the respondents in experimental and control groups were merged and analysed using ANOVA to test if the differences observed in the physical health perceptions of inmates in Ilesa Prison were statistically significant. Table 3 showed that the calculated F-ratio of 19.617 for inmates perception of their physical health was significant at $p=0.000$ when tested at 0.05 level of significance. The findings show that there is a relationship between sport participation and physical health perception in Ilesa Prison.

The results of multiple regression analysis in Table 4 shows that physical health of the inmates increases as they participated in athletics $(\beta=7.212)$. Furthermore, the result of the t-test shows that the contribution of athletics in increasing the physical heath of the inmates is statistically significant $(p=.000)$. Again, findings revealed that inmates' physical health $(\beta=0.465)$ increases with increase in participation in badminton. Similarly, the contribution of this sport to inmates' physical health is statistically significant. The result of t-test $(\mathrm{t}=5.403$; $p=.002$ ) confirmed this. Likewise, the results of multiple regression shows that participation of inmates in Table Tennis increases their physical health $(\beta=1.431)$. The result of the t-test further shows that the contribution of Table Tennis in increasing the inmates' physical health is statistically significant. This was significant at $(\mathrm{t}=7.330$; $p=.000)$. The results of multiple regression shows that physical health of the inmates increases as they participated in volley ball $(\beta=0.982)$. Furthermore, the result of the t-test shows that the contribution of volley ball in increasing the physical heath of the inmates is statistically significant ( $p=.001$ ). The cumulative $R$-square for these entire variables was put at 0.718 . The coefficient of determination (R-square) indicates that the model adequately fit the data. This implies that about $71.8 \%$ variance in physical health of the inmates was explained by all the predictors variables entered into the regression model.

Table 2. Mean and Standard Deviation of Sport Participation and Physical Health Score

\begin{tabular}{|c|c|c|c|c|c|c|c|c|c|}
\hline \multicolumn{2}{|c}{ Subjects } & \multicolumn{4}{c|}{ Sport Participation Score } & \multicolumn{4}{c|}{ Physical Health Score } \\
\cline { 3 - 11 } \multicolumn{2}{|c|}{} & $\begin{array}{c}\text { Athletics } \\
\mathrm{N}=16\end{array}$ & $\begin{array}{c}\text { Badminton } \\
\mathrm{N}=16\end{array}$ & $\begin{array}{c}\text { Table Tennis } \\
\mathrm{N}=14\end{array}$ & $\begin{array}{c}\text { Volley ball } \\
\mathrm{N}=24\end{array}$ & $\begin{array}{c}\text { Athletics } \\
\mathrm{N}=16\end{array}$ & $\begin{array}{c}\text { Badminton } \\
\mathrm{N}=16\end{array}$ & $\begin{array}{c}\text { Table Tennis } \\
\mathrm{N}=14\end{array}$ & $\begin{array}{c}\text { Volley ball } \\
\mathrm{N}=24\end{array}$ \\
\hline \multirow{2}{*}{ Experimental } & Mean (X) & 5.34 & 5.09 & 5.96 & 5.40 & 25.28 & 24.81 & 24.79 & 27.85 \\
\cline { 2 - 11 } & $\mathrm{SD}$ & 2.548 & 2.988 & 3.294 & 2.819 & 6.962 & 8.982 & 9.406 & 9.198 \\
\hline \multirow{2}{*}{ Control } & Mean (X) & 3.41 & 3.75 & 3.07 & 4.35 & 23.31 & 17.44 & 17.25 & 23.90 \\
\cline { 2 - 11 } & SD & 1.341 & .842 & .858 & 1.564 & 3.578 & 5.924 & 6.507 & 5.137 \\
\hline
\end{tabular}

Table 3. Analysis of variance of the relationship between sports participation and physical health

\begin{tabular}{|c|c|c|c|c|c|}
\hline \multicolumn{6}{|c|}{ ANOVA } \\
\hline \multicolumn{2}{|c|}{ Physical Health } & & & & \\
\hline & Sum of Squares & $\mathrm{df}$ & MS & $\mathrm{F}$ & Sig. \\
\hline Between Groups & 7433.911 & 10 & 743.391 & 19.617 & .000 \\
\hline Within Groups & 10193.574 & 269 & 37.894 & & \\
\hline Total & 17627.486 & 279 & & & \\
\hline
\end{tabular}

$\mathrm{P}<0.05$.

Table 4. Coefficients of regression analysis between sport participation and physical health perception

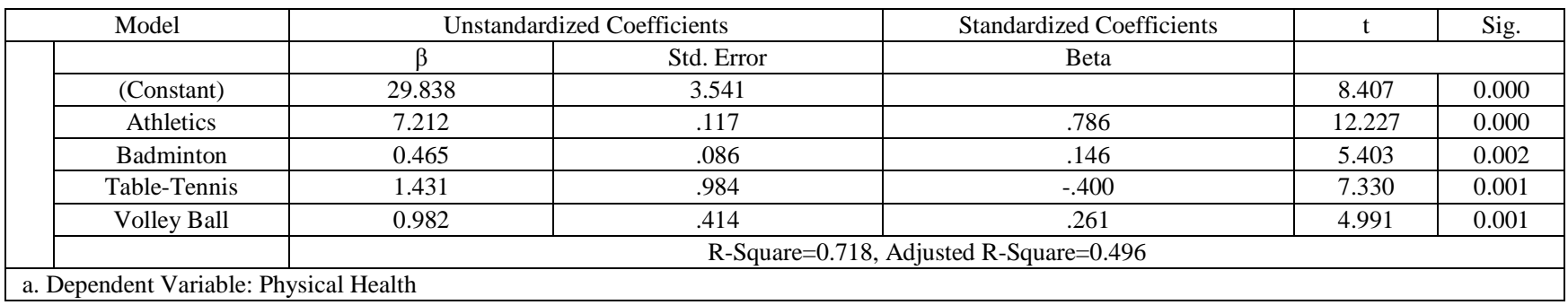


Table 5 below shows the Pearson's Product Moment Correlation Coefficients of participation in sub-groups of Athletics (sprint and relays), Badminton, Table Tennis and Volleyball and Perceived physical health of inmates in Ilesa Prison. It was observed that there is a correlation between participation in athletics and physical health $(\mathrm{r}=0.685)$ which is significant at $(\mathrm{P}<.05)$. It is therefore concluded that relationship between athletics and physical health is statistically significant. It was further observed that there is a moderate correlation between participation in badminton and physical health $(\mathrm{r}=.555)$ which is significant at $(\mathrm{P}<.05)$. Also, there is a correlation between participation in Table Tennis and physical health $(\mathrm{r}=.697)$ which is significant at $(\mathrm{P}<.05)$ while there is a moderate correlation between volleyball participation and quality of life $(\mathrm{r}=.504)$ which is significant at $(\mathrm{P}<.05)$. It is therefore concluded that there is a positive and statistically significant relationship between participation in different sports and physical health among inmates of Ilesa prison.

Table 5. Pearson's Product Moment Correlation Coefficients of Sport Participation and Physical Health by Sport Group

\begin{tabular}{|c|c|c|}
\hline & \multicolumn{2}{|c|}{ Correlations } \\
\hline Sport Participation Group & & Physical Health \\
\hline \multirow{2}{*}{ Athletics } & Pearson Correlation & $.685^{* *}$ \\
\cline { 2 - 3 } & Sig. (2-tailed) & .000 \\
\hline \multirow{2}{*}{ Badminton } & Pearson Correlation & $.555^{* *}$ \\
\cline { 2 - 3 } & Sig. (2-tailed) & .000 \\
\hline \multirow{2}{*}{ Table-Tennis } & Pearson Correlation & $.697^{* *}$ \\
\cline { 2 - 3 } & Sig. (2-tailed) & .000 \\
\hline \multirow{2}{*}{ Volleyball } & Pearson Correlation & $.504^{* *}$ \\
\cline { 2 - 3 } & Sig. (2-tailed) & .000 \\
\hline
\end{tabular}

$\mathrm{P}<0.05$.

Based on the results of this study, it is concluded that there is positive relationship between participation in different sports and perceived physical health among inmates of Ilesa Prison in Osun State, Nigeria.

\section{Discussion}

The findings showed that participation in different sporting activities - athletics, table tennis, badminton and volleyball enhances physical health of prison inmates. These findings agreed with previous studies that sport improves the physical health aspect of quality of life among general populations [18]. The findings also agreed with previous reports that sport is a viable programme for promoting good health as it has a positive impact on health risks and general wellness $[4,19]$ General opinions agreed that sport is a viable method of promoting good health; particularly, it was agreed that regular physical activity has a positive impact on health risks such as heart diseases, obesity, hypertension, osteoporosis and diabetes among general and convalescent population [3,19,20].

\section{Conclusion}

Organising sporting activities as parts of prison routine will go a long way in preventing debilitating ailments and promote physical health, fitness and general wellbeing of population undergoing corrections and rehabilitation programmes during confinement.

\section{Limitations of the Study}

The respondents were limited to male inmates within the age of 20 and 35 years for maximum participation. More than 48 percent of inmates below 20 and above 35 years were excluded from the study due to age. The results of the study may not be applicable to female prisoners and male inmates outside the age between 20 and 35 years.

\section{Competing Interests}

The author declares that he has no competing interests.

\section{Acknowledgements}

The author expressed his appreciation to the Osun State Prison Command of the Nigeria Prison Services, the prison officers and the inmates of Ilesa prison for their support during the period of the study. The author particularly thank all the respondents for their commitment to the study and particularly appreciate their enthusiasm and for their renewed interest in a lawful society and in a law-abiding and promising future.

\section{References}

[1] Dunn, J., Assessment. In C.A. Peterson and S.L. Gunn (Eds.), Therapeutic Recreation Program Design: Principles and Procedures $\left(2^{\text {nd }}\right.$ ed.). Englewood Cliffs, NJ: Prentice-Hall, Inc. 1984, 267-320.

[2] European Union, Physical Activity Guidelines Recommended Policy Actions in Support of Health-Enhancing Physical Activity. Confirmed by EU Member State Sport Ministers at their meeting in Biarritz on 27-28 November 2008.

[3] World Health Organisation, Health and Development Though Physical Activity and Sport. Geneva, Wito Document Production Services, 2003.

[4] Coyle, A., A human rights approach to prison management. London, International centre for prison studies, 2002.

[5] Obadiora, AH, "Effect of Sport Participation on Quality of Life among Inmates of Ilesa Prison". A project thesis submitted in partial fulfilment of the requirements for the award of Doctor of Philosophy in Physical Education of the Obafemi Awolowo University, Ile-Ife, Nigeria, 2017.

[6] World Health Organization, Preamble to the constitution of the World Health Organization as adopted by the International Health Conference, New York, 19-22 June, 1946. Official Records of the World Health Organization, 2, 100.

[7] Schomer, H.H. and Drake, S.B., Physical Activity and Mental Health. International Sport Med J. 2001; 2(3). (C) 2001 International Federation of Sports Medicine.

[8] Brannon L. and Feist J., Health Psychol. Belmont, Calif: 2000, Brooks/Cole Pub Co.

[9] O’Neal H.A, Dunn AL, and Martinsen E.W., Depression and exercise. International Journal of Sport Psychology. 2000; 31: 110-135.

[10] Fox, K. R., Self- esteem, self- perception and exercise. International Journal of Sport Psychology, 2000b, 31: 228-240.

[11] Salokun, S. O. O., "Effects of Selected Sports Skill Training on the Self-Concept of Secondary School Adolescents in Oranmiyan Local Government Area of Oyo State, Nigeria”. Unpublished 
Ph.D. Thesis submitted to Institute of Physical Education, Obafemi Awolowo University, Ile-Ife, 1989.

[12] World Health Organisation, "Mental Health Promotion in Prison the WHO Health in Prison Project", The Hague, 2000.

[13] Scottish Prison Service, The health promoting prison: a framework for promoting health in the Scottish prison service. Edinburgh ,Health Education Board for Scotland, Woodburn House-Canaan Lane, 2002.

[14] Coalter, F., Realising the potential of cultural services: the case of sport. London, Pga publications, 2001.

[15] Shephard, R.J., Aging and Exercise. In: Encyclopedia of Sports Medicine and Science, T.D. Fahey (Editor). Internet Society for Sport Science: http://sportsci.org. 7 March 1998.
[16] WHO, WHOQOL User Manual. Division of Mental Health and Prevention of Substance Abuse. World Health Organization, Geneva, Switzerland, 1998.

[17] Oladimeji, B. Y., Psychological Assessment Techniques in Health Care. Obafemi Awolowo University Press Limited, Ile-Ife, Nigeria, 2005.

[18] McAuley, E. and Morris, K.S., Advances in Physical Activity and Mental Health: Quality of Life. American Journal of Lifestyle Medicine. Vol. X No. X. 2007.

[19] Emily, B. K., The effectiveness of interventions to increase physical activity: a systematic review. American journal of preventive medicine, 2002, 22: 73-107.

[20] American College of Sports Medicine, Osteoporosis and Exercise: a position stand. MSSE, 1995, 27, 1-7. 